\title{
Effects of Combretum obscurum Tul. almond and Carica papaya fruit seeds on intestinal parasites of captive-bred lemurs at the Parc Botanique et Zoologique de Tsimbazaza (PBZT) in the Madagascar.
}

\author{
*RAZAFIARISOA Berthine, RAZAIARIVELO Christine, RAMAROMILANTO Boromé, RAMAROKOTO Roger
}

\author{
Parc Botanique et Zoologique de Tsimbazaza (PBZT) \\ Rue Fernand Kasanga, Tsarafaritra, BP 4096 \\ Antananarivo 101 - Madagascar \\ * Corresponding Author: razafiari4@yahoo.fr \\ DOI: $10.31364 / S C I R J / v 9.103 .2021 . P 0321849$ \\ http://dx.doi.org/10.31364/SCIRJ/v9.i03.2021.P0321849
}

\begin{abstract}
Lemurs are among the specific and endemic animals of the mega biodiversity in the Madagascar. However, a large majority of their species is assigned to different degree of threat in the red list of IUCN. Captive bred conservation is one of the mission of the PBZT to ensure the survival of wild endemic animals by their reproduction and in mass education. Netherveless, life in a confinement needs more adaptations compared with life in the natural habitats. Despite a periodic conventional deworming program, worms' infestation are frequent and chronic in captivity. They lead to a permanent health problem and require an alternative solution which would not be harmful and not far from the natural habits of the wild animals. In this study, we try to highlight the potential of two plants well-known against intestinal parasites. Combretum obscurum Tul., an endemic plant and an introduced one, Carica papaya are both used in a randomized controlled trial study to appreciate their outcomes on deworming lemurs' intestinal parasites. Results are positive: treatment based on the Combretum obscurum Tul. almond and the Carica papaya fruit seeds are proven to be efficacy to deworm intestinal parasites of lemurs. They could be used safely as a complementary treatment as well as conventional deworming medicines. In addition, they are not far from the natural habits of lemurs and are easier to implement with a minimal risk to develop resistance. They may be a secure sustainable alternative solution to deworm captive lemurs.
\end{abstract}

Keywords: Carica papaya, Combretum obscurum Tul., deworming, endoparasites, lemurs

Madagascar biodiversity is well-known in the world for its endemism |12]. Lemurs' family is one of a specific and endemic animals in the Madagascar. Many of them are assigned in the red list of IUCN with different degree of threat 17]. In 2012, ninety four among one hundred and three lemurs' species are recorded in a danger of extinction. Human activities as, deforestation, hunting, poaching and illicit trade make a permanent stress on them. Despite of the agreement in the Convention on International Trade in Endangered Species of Wild Fauna and Flora (CITES) by the Madagascar (1975), the IUCN Red List declared that twenty three species of lemurs are classified in "Critical Danger", fifty two are "Endangered", nineteen "Fragile" and three are "Near Threatened". Only three species are not a focus in conservation because ordered at "Least Concerned" degree. According Mongabay site [15], ninety per cent of the Madagascar lemuridae are on the limit of extinction.

Captivity-bred is one of the strategy settled to conserve the endemic wild animals. It aims to ensure the survival of the species in mass education and in their reproduction. However, if natural habitats offered more option for feeding or healing, the confinement needs more adaptations to ensure the wellbeing of the animals. In captivity, worms' intestinal infestation is frequent despite a periodic conventional deworming program. Endoparasites are both pervasive and become a source of a chronic disease for captive-bred animals [3], [4]. The situation requires more attention because by parasites chronic infestations could lead to other serious health problems which are fatal for lemurs most of the time. 
In the Madagascar, some plants are traditionally used against human or animals intestinal worms' infestation. In this randomized controlled trial study, the effectiveness of two plants on deworming are tested for the first time with lemurs' captive bred. One of them is the Combretum obscurum Tul. , an endemic plant and the other, the Carica papaya, an introduced plant. Comparison of their efficiency with a conventional deworming treatment drug will allowed to develop a complementary prophylactic answer against intestinal worms which is not far from the natural habits of the animals.

\section{MATERIALS AND METHODS}

\section{Materials}

The Combretum obscurum Tul. is an endemic creeping plant, listed in the Madagascar Flore from 1856 |5]. It is well-known to have a deworming medicinal proprieties |2], |14]. The Carica papaya is native from Mexico and northern South America |8], |11]. It is an unbranched stem tree which grows very quickly in different tropical countries. According different scientific studies, the anthelminthic properties of papaya fruit seeds are proven on children |2], |10] and on chicken |1]. It is used for the first time on lemurs.

Preparation with the Combretum obscurum Tul. is based on mixture of almonds (Photo1) creased with peanut, garlic cloves at the proportion $100 \mathrm{~g} / 50 \mathrm{~g} / 4$, then sweated with artisanal sugar. For the Carica papaya, fruit seeds (Photo 2) are dried and crushed to powder.

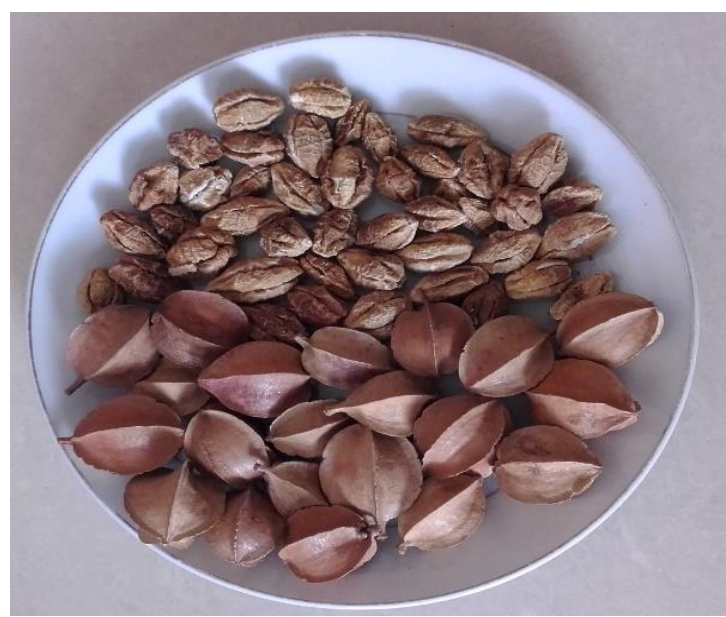

Photo1: Combretum obscurum Tul. almond (Source PBZT)

\section{Characteristics of the animals}

The study enrolled fifty six species of lemurs reserve intended to thematic research at the Tsimbazaza Park. The species are: Eulemur Albifrons, Eulemur Coronatus, Eulemur Fulvus, Eulemur Rubriventer, Eulemur Rufus.

Global characteristics of the lemurs are reported in Table 1.

Table 1: Global characteristics of the lemurs enrolled

\begin{tabular}{|l|c|c|c|}
\hline \multicolumn{1}{|c|}{ Scientific name } & Characteristics & IUCN Status (1) & Number of species \\
\hline$\underline{\text { Eulemur Albifrons }}$ & White-fronted brown lemur & Rare (R) & 7 \\
\hline$\underline{\text { Eulemur Coronatus }}$ & Crowned lemur & Endangered (E) & 12 \\
\hline$\underline{\text { Eulemur Fulvus }}$ & Brown lemur & Rare (R) & 17 \\
\hline$\underline{\text { Eulemur Rubriventer }}$ & Red-bellied lemur & Vulnerable (V) & 7 \\
\hline$\underline{\text { Eulemur Rufus }}$ & Red fronted lemur & Rare (R) & 13 \\
\hline
\end{tabular}


(1) The criteria for threat Status of IUCN are: i) Endangered (E) when the taxa is in danger of extinction and the survival is doubtful. ii) Vulnerable (V): taxa believed likely to move into the "Endangered" category in the near future, iii) Rare (R), taxa with small world populations that are not at present "Endangered" or "Vulnerable", but are at risk if the causal factors continue to operate.

At the PBZT, lemurs are fed once a day at noon. Meals are based on seasonal fruits: bananas, mangoes, apples, peaches, papayas, etc ... and vegetables: carrots, tomatoes, beans, salad, cabbage, etc.... Some days, eggs and bread are added. A deworming prophylactic program based on Fenbendazole $5 \% \mathrm{mv}$ is scheduled every two months, alternatively with Ivermectine $10 \mathrm{mg} / \mathrm{ml}$, in order to up the scope of the treatment against a wide variety of the worms as roundworms, hookworms, whipworms and some tapeworms.

\section{Study design}

The study is carried out on February to March 2020 at the PBZT. A randomized controlled trial method is used to appreciate the outcomes on the two studied plants. Lemurs are assigned in three (3) experimental groups: Group 1: Control group which concerns nineteen lemurs $(n=19)$ cured with a classic deworming drug, the Fenbendazole 5\%, Group 2: Almond group which involves eighteen lemurs $(\mathrm{n}=18)$ treated by Combretum obscurum Tul. and Group 3: Papaya group which includes nineteen lemurs $(n=19)$ treated by papaya fruit seeds. Distribution of the group is assigned in Table 2.

Table 2: Distribution of the lemurs group

\begin{tabular}{|l|c|c|c|c|}
\hline \multicolumn{1}{|c|}{ Scientific name } & Group 1 & Group 2 & Group 3 & Total \\
\hline Eulemur Albifrons & 4 & 2 & 1 & 7 \\
\hline Eulemur Coronatus & 5 & - & 7 & 12 \\
\hline Eulemur Fulvus & 5 & 8 & 4 & 17 \\
\hline Eulemur Rubriventer & 2 & 5 & - & 7 \\
\hline Eulemur Rufus & 3 & 3 & 18 & 13 \\
\hline Total & 19 & 18 & 56 \\
\hline
\end{tabular}

During the experimentation, lemurs are indiscriminately disseminated in 18 experiment random cages with 2 or 3 animals in each, without species or sexes distinction (Photo 3, Photo 4). 


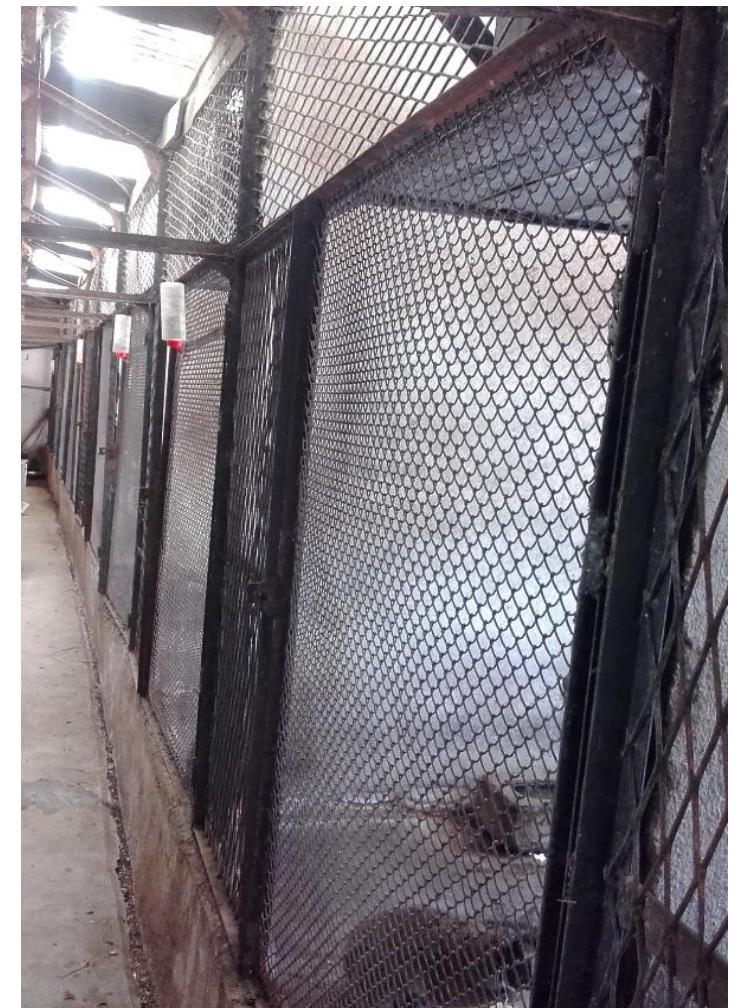

Photo 3: Experiment cages (Source PBZT)

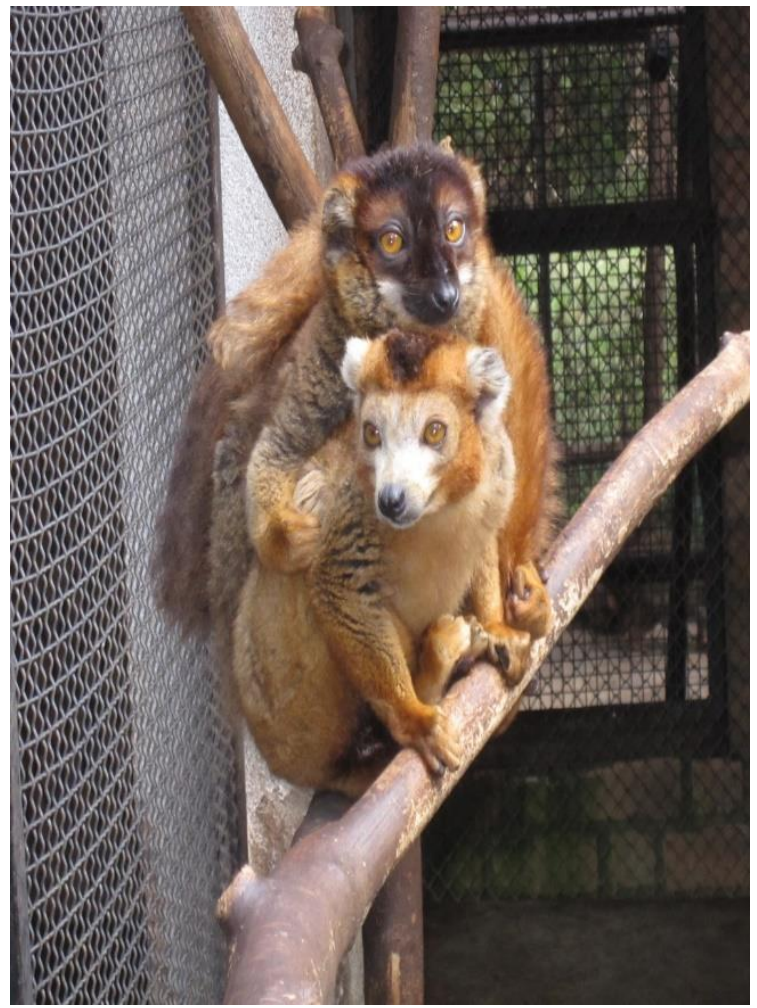

Photo 4: Eulemur Fulvus (above) and Eulemur coronatus (below) (Source PBZT)

Every day, two hours before meals, lemurs in the "Group 2" and the "Group 3" received $4 \mathrm{~g}$ of each preparation during the 4 days of experimentation. They are mixed with a banana portion to ensure the palatability and the total consumption.

For the control group (“Group 1”), the Fenbendazole 5\% mv is given at the first day after fecal collect.

The monitoring is based on diagnosis of the eggs in the lemurs' feces. This method is the most accessible and the least intrusive way to study the intestinal parasites. It is used over the past twenty years |9]. However, determination based on eggs does not go beyond the level of the genus or the family of the parasites.

Fresh feces are collected at the morning after the cages cleaning, in a clean pot with a liquid conservation alcohol $70^{\circ} \mathrm{C}$. Multiple samples are collected to increase the probability of detecting eggs parasites. Samples are collected before the treatment on the first day (D1) and at the Day 5. A total of 112 fecal samples has been collected. Then, the samples are analyzed at the National Veterinary Parasitology Laboratory (LNDV) for the identification of the eggs parasites. Two methods are used: i) the flotation technics by Sodium Chloride $(400 \mathrm{~g} / 1000 \mathrm{ml}$, density= 1, 2) where light helminthes eggs are recovered in the supernatant of fecal samples and ii) the sedimentation centrifugation technics with distilled water to separate the specific portion of the feces containing intestinal parasites. Then, the eggs of the parasites type are detected with a microscopic examination |6].

\section{Statistical analysis}

The rate of parasite infection is defined by the percentage of the eggs expelled in the feces. Excel 2013 and SPSS 25 are used for the data statistical analysis and to establish the relationship between variables. The Pearson's correlation coefficient $r$ with $p$-value permit to confirm the relationship between the variables Day 1/Day 2 and between the variable control "Group 1" with "Group 2" and "Group 1" with "Group 3". The p-value states the statistical significant of the results and the Pearson's correlation coefficient $\mathrm{r}$ measures the relationship between the variables' association |13]. If p-value is lower than the conventional value $5 \%(\mathrm{P}<0.05$ ), the correlation coefficient is statistically significant: there is a correlation between the variables and the null hypothesis failed. The coefficient $r$ gives information about the nature and the magnitude of that association: if $r$ is close to 0 , there is no linear relation between the two variables. There is a negative linear relationship at the value $r=-1$ and the relationship is positive with a value closes to +1 .

\section{RESULTS AND DISCUSSION}

Type of the parasites eggs expelled 
The results is based on 110 complete data fecal samples. Photo 5 and Photo 6 show some kind of eggs detected in the lemurs' feces samples.

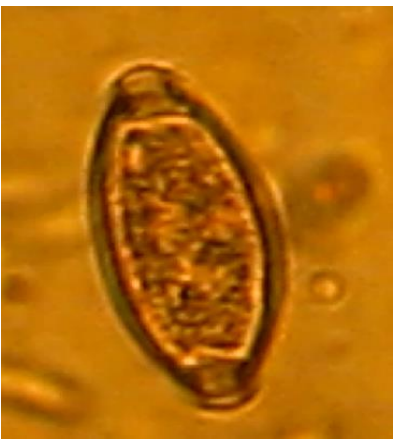

Photo 5 : Eggs of Trichuris $s p$ parasite in lemur feces (Source PBZT)

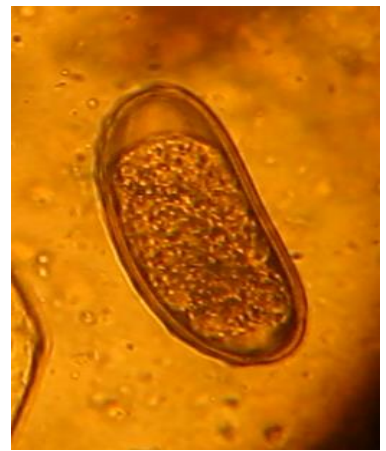

Photo 6 : Eggs of Oxyuridis parasites in lemur feces (Source PBZT)

Prevalence of the lemurs' safe, without fecal eggs parasites, were only twenty nine percent (29\%). Among the 56 lemurs enrolled, polyparasitism is not be omitted. The proportion of the infection by helminthes is higher $(69 \%)$ comparatively with the situation by year $2000(57 \%)$ |4]. Nematoda (roundworms) is present among fifty nine percent of fecal samples (59\%) if the rate of flatworms Platyhelminthes/Cestoda is ten percent (10\%). Among the parasites, a significant helminthes eggs are not identified: twenty two percent $(22 \%)$ for Nematoda and forty five percent (45\%) for Cestoda. Protozoa eggs as Eimeria are identified too (number $=3$ ). The degree of the parasites infection is: i) Nematoda: Trichonstrongylids (25\%), Strongloïdes (18\%), ii) thornyheaded worms Acanthacephalan (14\%), Ascaris 12\%), Oxyurids sp (8\%) and iii) Ankylostoma (2\%). The type of Cestoda was Cyclophylidien (36\%) and Hymenalopsis (18\%). Figure 1 shows the distribution of the eggs parasites in the samples.

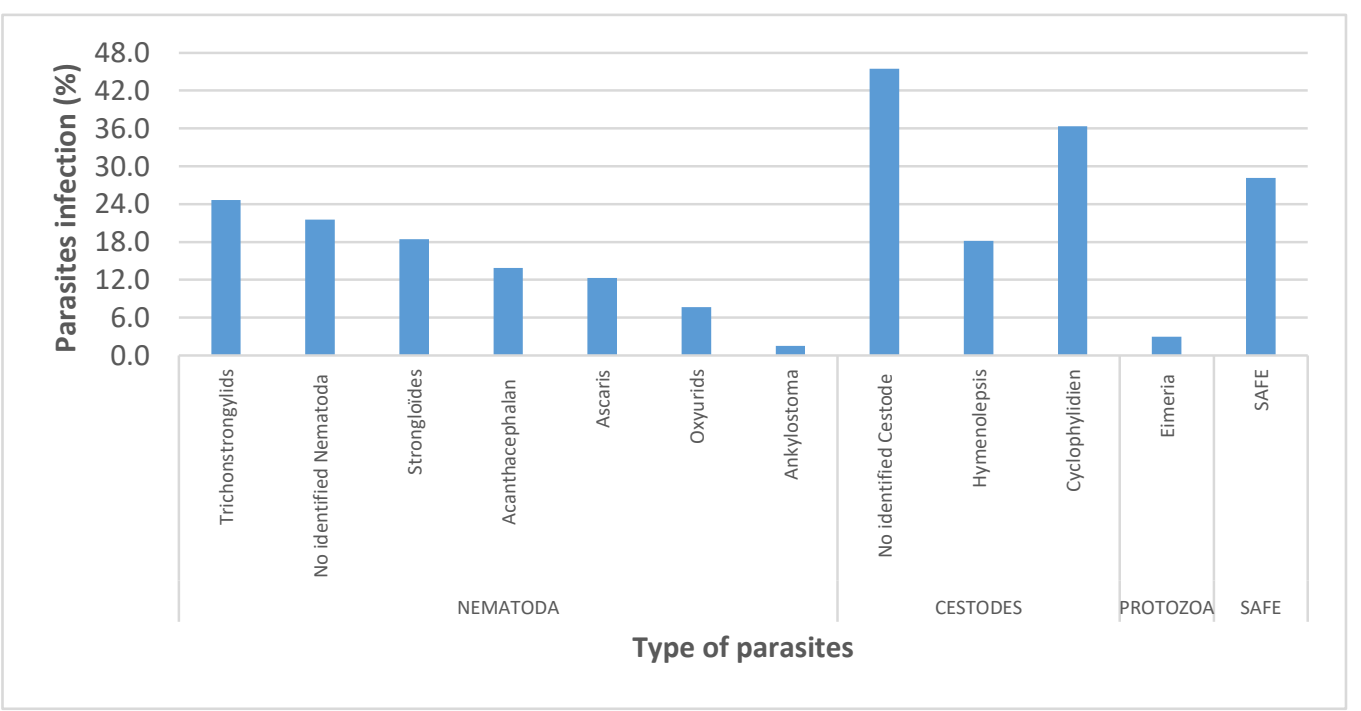

Figure1: Distribution of the eggs parasites in the samples (per cent)

\section{Comparison of the parasites eggs expelled between Day 1 and Day 5}

Between Day 1 and Day 5, the number of the total expelled eggs increases from Number $=24$ to Number $=55$. Some parasites eggs are only expelled at the Day 5 as, Ankylostoma, Ascaridia, Hymenalopsis, not identified Cestoda and Eimeria.

At the Day 5, the number of eggs expelled increases for the majority of intestinal parasites. It declines for Oxyurids sp and is without changes for Trichonstrongylids. The graph shows a linear relationships of the results (Figure 2). 
Figure 2: Distribution of the parasites eggs expelled on Day 1 and Day 5 (number)

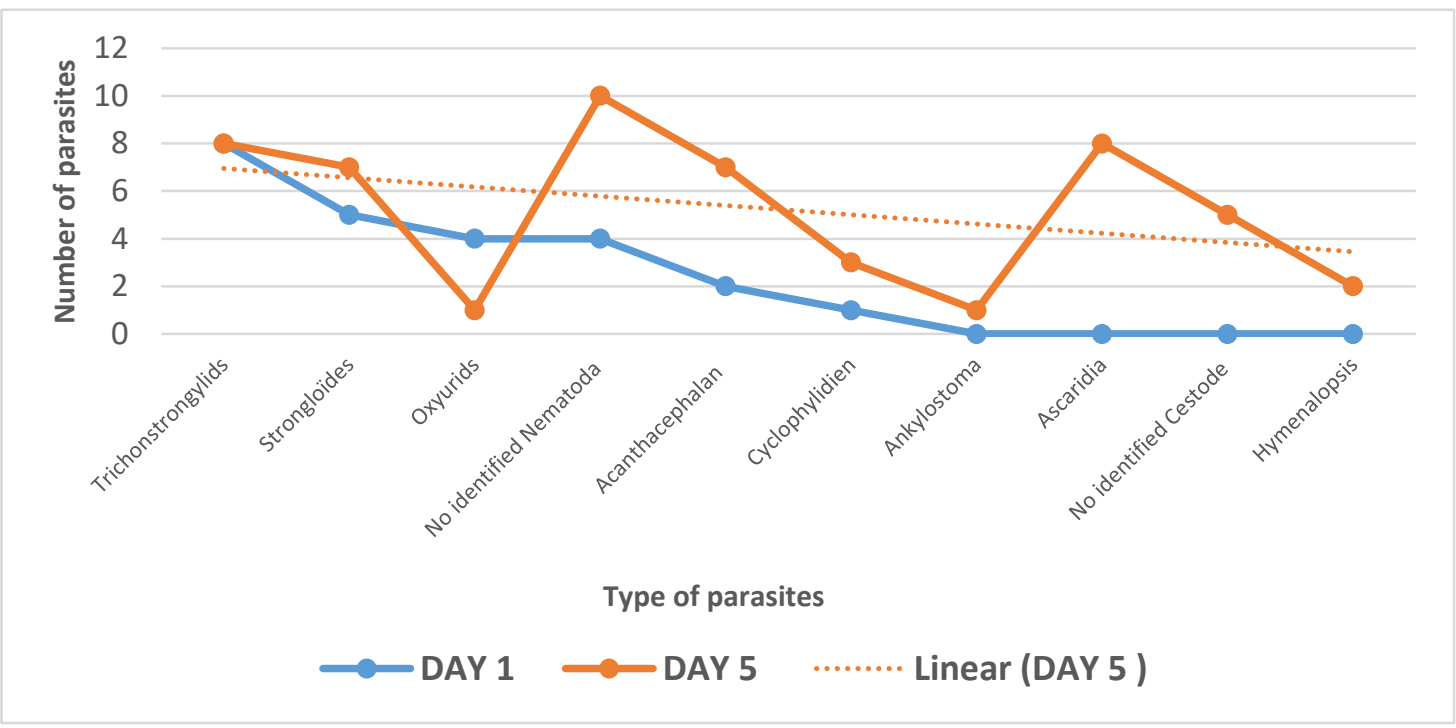

The Pearson correlation coefficient value is high $(\mathrm{r}=0.78)$ and the correlation is statistically significant with $p$-value $=0.00$. The null hypothesis failed. Briefly, fecal parasites eggs expelled increased both in number and in kind between the Day 1 and the Day 5 of the experimentation.

\section{Comparison of the parasites eggs expelled between the 3 Groups}

Different kinds of parasites are ejected in the feces of each 3 groups treated. Apparently, the 3 treatments have a similar effect on eggs expulsion of Acanthacephalan and Strongloïdes. More eggs of Trichonstrongylids, Ascaridia, Oxyurids and Hymenalopsis are ejected with the treatment based on Combretum obscurum Tul. almond and on papaya fruit seeds.

For the control group (Group 1), the ejection of Oxyurids, Ankylostoma and Hymenalopsis is lacking although more of "not identified cestoda" are expulsed. In the feces of the Group 3 treated with papaya, the expulsion of the parasites eggs of Ankylostoma and Eimeria is deficient. The distribution of parasites eggs among the 3 groups are shown in Figure 3.

Figure 3: Distribution of parasites eggs among the 3 Groups (number)

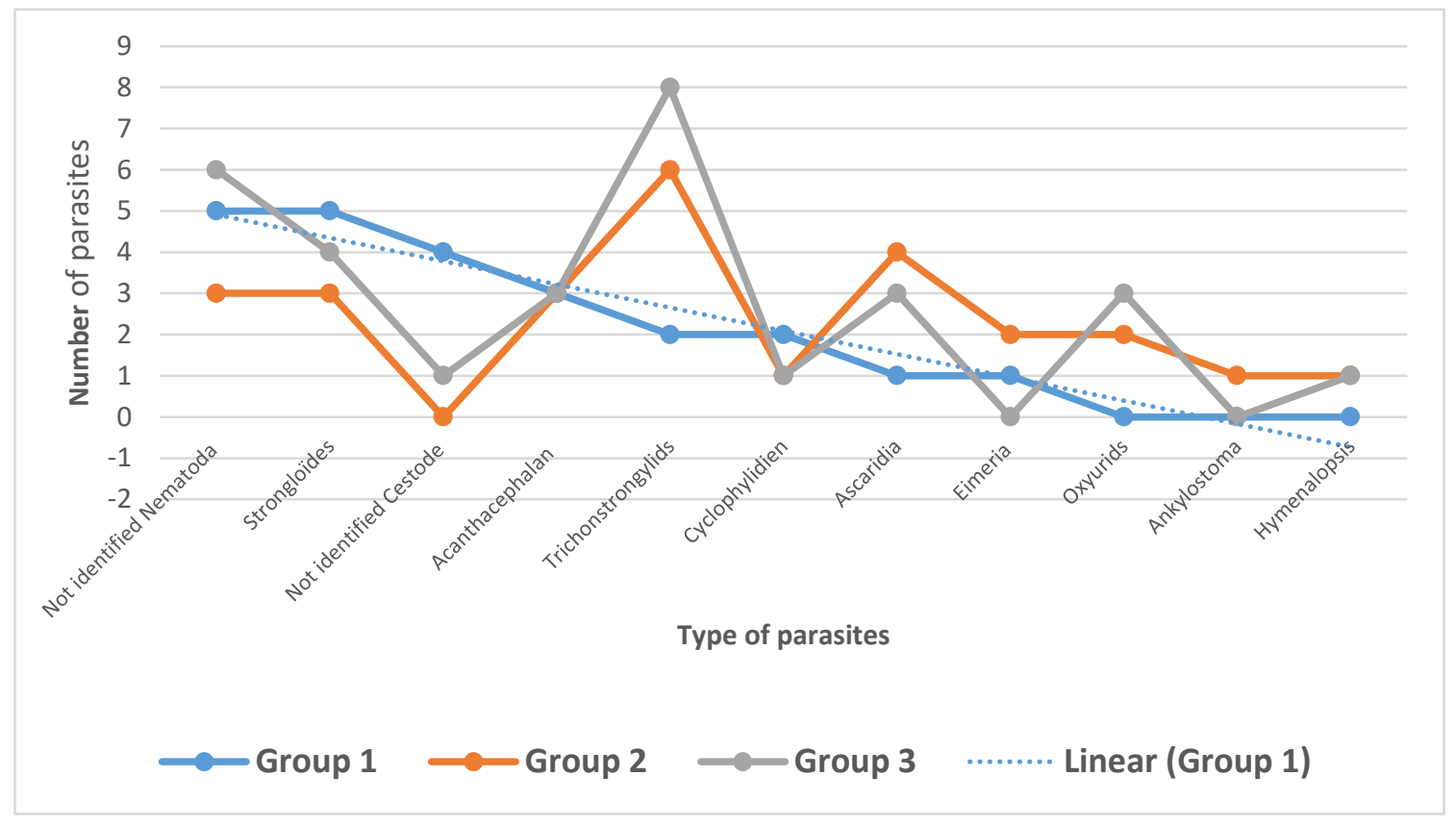


There is a high relationship between the control Group 1 and the Group 2 with a coefficient $r=0,61$ at a palue $=0$, 03: the link is statically significant and strong. Moreover, the treatment based on Combretum obscurum Tul. almond is more efficiency to expulse eggs of Oxyurids, Ankylostoma and Hymenalopsis, compared with classic conventional deworming based on Febendazole 5\% mv.

Between the control Group 1 and the Group 3, a high degree of relationship is detected. Both Febendazole drug and $\underline{\text { Carica }}$ papaya fruit seeds are efficient in deworming intestinal parasites: the Pearson correlation coefficient is high $\mathrm{r}=0,73$ with $\mathrm{p}$ value $=0,00$. If the use of drug takes advantages on expulsing protozoa, the papaya treatment is more efficiency against Oxyurids and Hymenalopsis.

Efficacy of the treatment based on the Combretum obscurum Tul. almond and the Carica papaya fruit seeds to deworm intestinal parasites of lemurs are proven in the study.

\section{CONCLUSION}

Extinction of the wild endemic animals in their natural habits is a real risk in the Madagascar. Conservation of lemurs is mostly required. All the lemur species enrolled in the study is concerned at different degrees of threat. The conservation in captivity is an incentive strategy but needs specific attention mostly with worms' infections. The results have shown the effectiveness of the treatment for lemurs captive-bred, based on the Combretum obscurum Tul. almond and the Carica papaya fruit seeds against intestinal parasites as well as conventional deworming medicines. They may be an alternative option and could be used safely as a complementary treatment against intestinal parasites of wild animals. They offer a secure sustainable alternative solution, not far from the natural habitats of the animals and take the advantage of to be easier to implement.

\section{REFERENCES}

1. BEDE P. OZARAGA Ma.. OZARAGA Sylvia I,. BARRIO Marineth B., 2020 : Process of preparing a papaya (Carica papaya) deworming composition for chickens, Invention Development Division, Capiz State University (CapSU), Registration Number: 2-2015-000496, https://techtrans.gov.ph/utility-models/process-preparing-papaya-carica-papayadeworming-composition-chickens

2. BENAVIANA, 1994: Nématodoses intestinales affectant les enfants de 1 à 5 ans dans la ville de Mampikony et les plantes médicinales utilisées dans leur traitement, (Oxyurose, Ascaridiose, Trichocéphalose, Ankylostomose et Anguillulose). Université d'Antananarivo ;

3. BLANCOU J. et R. ALBIGNAC, 1976. Note sur l'infestation des Lémuriens malgaches par Spirocerca lupi (Rudolphi, 1809) par (*"), Rev. Elev. Mkd. Vét. Pays trop., 29 (2) : 127-130.

4. COIFFIER O. C. S., 2000. Contribution à L'étude des helminthes digestives des lémuriens appartenant aux genres Lémur et Eulemur au Parc Zoologique de Tsimbazaza. Thèse pour le Doctorat Vétérinaire. Faculté de Médecine de Créteil. Ecole Nationale Vétérinaire d'Alfort. France

5. CONSERVATION ET JARDIN BOTANIQUE DE GENEVE, CJB, 2012 : African Plant Database: Ann. Sci. Nat., Bot., sér. 4 6: 83 (1856), Record n²05199 created 2009-08-19, http://www.villege.ch/musinfo/bd/cjb/africa/details.php?langue=an\&id=205199

6. FOREYT, WILLIAM J., 2001: Veterinary Parasitology Handbooks. Fifth Edition, Blackwell Publishing, Iowa State University, ISBN 0-8138-2419-2.

7. HARCOIUT C, and THOMBACK J. , 1990: Lemurs of Madagascar and the Comoros. The IUCN Red Data Book. IUCN, Gland, Switzeriand and Cambridge, U.K.

8. HEYWOOD V.H; BRUMMITT RK; CULHAM A; SEBERG O , 2007. Flowering plant families of the world. Firefly Books. ISBN 9781554072064.

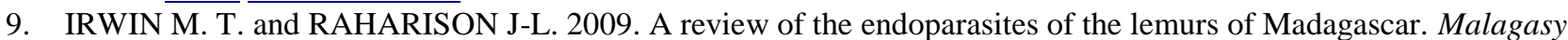
Nature, 2: 66-93.

10. KUGO M., KETER L., MARYO A., KINUYA J., NDEMWA P., MAINA G., OTIENO P. and E. SONGOK E. M., 2018. Fortification of Carica papaya fruit seeds to school meal snacks may aid Africa mass deworming programs: a preliminary survey. BMC Complementary and Alternative Medicine (2018) 18:327. https://doi.org/10.1186/s12906018-2379-2

11. MORTON JF (1987). "Papaya". NewCROP, the New Crop Resource Online Program, Center for New Crops \& Plant Products, Purdue University; from p. 336-346. In: Fruits of warm climates, JF Morton, Miami, FL. Retrieved 23 May 2015.

12. RUSSEL A. MITTERMEIER, T BROOKS T., FONSECA G. et BRITO D., 2007. Focus : les pays de mégadiversité », dans Pierre Jacquet et Laurence Tubiana, Regards sur la Terre 2008, Paris, Presses de Science. ISBN 9782724610437, , p. 153-154.

13. RAKOTOMALALA R., 2017. Analyse de corrélation : Étude des dépendances - Variables quantitatives. Université Lumière Lyon 2. 
14. SOCIETE DES AMIS DU PARC BOTANIQUE ET ZOOLOGIQUE DE TANANARIVE, 1942. Plantes médicinales. Exposition de simples gens, PP 18. Imprimerie Moderne de l'Emyrne, Pitot de la Beaujardière, Tananarive .

15. Webiographie : https://fr.mongabay.com/2012/09/91-des-lemuriens-de-madagascar-menaces-dextinction/, Mongabay.com on 12 Septembre 2012.

\section{Acknowledgements}

We thank Ratsimbazafy J. Adolphe and Rakotondravony F. Honoré, technicians at the Mammal Class Division /PBZT and all the team of Laboratoire National de Diagnostic Vétérinaire for their support during the study. 